\title{
Response of Environment According to the Sustainable Urban Design Principles (Case Study: Garden of Imam Reza (AS) in Koohsangi Avenue, Mashhad, Iran)
}

\author{
Rokhsaneh Derakhshesh Nia ${ }^{1,}$, Maryam Hazzar ${ }^{2}$ \\ Department of Urbanism, Faculty of Art and Architecture, Imam Reza International University, Mashhad, Iran
}

Email address:

d.rokhsaneh@yahoo.com (R. D. Nia),maryamhazzar@yahoo.com (M. Hazzar)

To cite this article:

Rokhsaneh Derakhshesh Nia, Maryam Hazzar. Response of Environment According to the Sustainable Urban Design Principles (Case Study: Garden of Imam Reza (AS) in Koohsangi Avenue, Mashhad, Iran). International Journal of Science, Technology and Society. Special Issue: Research and Practice in Architecture and Urban Studies in Developing Countries. Vol. 3, No. 2-1, 2016, pp. $150-156$.

doi: $10.11648 /$ j.ijsts.s.2015030201.38

\begin{abstract}
In recent decades, the negative effects of the global movement of modernism in Iran and uncoordinated urban development has led to the city and other urban spaces that do not belong the people. Sense of alienation and un-belonging to such areas are strengthening day by day and irregular construction in the city has resulted in loss of urban green spaces. Urban green spaces used by people in Iran has showed that the majority of cities in terms of quantity and quality in the provision of these spaces are not at the right level. This means that in most cases the spaces are not according to the needs and interests of users. This leads to a lack of coordination between the individual and the environment and which have not assigned the correct and appropriate characteristics. Regarding the issue of urban green space, once more people appear to know the city uses it is more directly related to urban sustainability and values, as well as the quality of urban spaces in such a way that there is a close relationship between quality and sustainability concepts. The purpose of this paper is to define and articulate its relationship with the utility space sustainable spaces have tried to evaluate the effect of the garden of Imam Reza (AS) of respondents to its surroundings and citizens of Koohsangi Avenue.
\end{abstract}

Keywords: Respondents Environment, Sustainable Urbanization, the Garden of Imam Reza (AS)

\section{Introduction}

The city as a living organism, people and activities, "Spirit" and the body of the city as the "body" of these organisms are. City during their life as a result of various factors, changes shape and grows, but the good city that is his body provides needs of people with changes in the body's city [1]. Housing and life in the big house as a home should have the attributes and benefits to live a good life and the welfare sector, The city also has the qualities and features to ensure comfort, warm, friendly and pleasant environment like home life more prosperous and desirable. To the fact that people of faith have influenced their environment [2]. Acceleration of modern life in urban and urban culture, has resulted decrease in communication and social interaction of citizens with each other and paved the way to neglect the importance of public space for social interactions. Hence, nowadays in urban settlements, especially in major cities, direct contact with natural environment, are minimal or nothing [3]. Sense of alienation is among the problems that currently plague the people of the world. It's issue all over, appear between people and built environment while public green spaces needs both in terms of needs environmental and aspects platform of social communication rightful place is important. But, changes in the needs of people with the passage of time has caused the structure of green spaces is therefore the structures of modern thought and a kind of conflict there in the minds of users, followed by the lack attention of urban green space is happening. Therefore, the use and development of green spaces may have direct effects on the psyche of people and These problems lead us to think who are looking for the effect of exist green space on the people of the city of Mashhad, and will found the factor that protects these places by the people and the authorities in the results.

\section{Problem Statement}

Lack of attention to the human aspects of the design and 
architecture of urban spaces in cities leads to mental and social health is in danger. One of the factors that cause such problems is the lack of green space in a city and the structure and the presence of green spaces in the structures of modern thought and the body is almost traditional, the other users do not match with the modern thought. Then clients have direct effects on the psyche, followed by the amount of attention to the use of green spaces decreases. The problem of the city's physical changes due to technological advances and the need to meet new needs and demands of people to kill or not to lack preserve green space, one of the main issues today is painful, Therefore, this article tries to answer with regard to the amount of green space in the city as an open space, increase the tendency of the people and authorities to preserve green space. This article assumes that this urban space is sustainable and dynamic space and the people who live in Koohsangi street tend to keep their green gardens.

\section{Research Methodology}

Although the importance of this qualitative study, but due to extraction certain criteria measurable and quantitative, a combination of qualitative and quantitative strategies in correlation method is used. The purpose of the respondents in this area were reviewed and questions such as "Is green space is on track to increase security? Is space for interaction and daily appointments and participation in various activities have been carried out? Is the main basis for achieving the purpose of this study considered?

The nature and purpose of the research is qualitative and quantitative because the extraction of measurable and quantitative criteria, a combination of qualitative and quantitative strategies in correlation method used. Outdoor green space features independent variable and the dependent variable is the response rate. Data extraction tools to fit the environmental characteristics of the territory, the study of the selected field. In this study population through field observations are times to 8 times each morning and evening for 15 minutes has been obtained at different times of day. So that the number of pedestrians in the area reached 200 of the 112 questionnaires were obtained in Cochran formula. The respondents were selected at random from each crossing and with collected responses to this questionnaire and use spss software chi-square test results were analyzed.

\section{Related Study}

Sustainable development is a concept that in recent years has been seen as a global problem. The first Habitat Conference was introduced in Canada in 1976. The concept of sustainable development since the early 1980s, during the ten years of unbridled growth in the name of development in terms of the quality of the environment on a global scale. This theory is presented in order to protect natural resources. Wide sustainable development goals and for the first time in 1987 was defined by Brant Land [4]. Wced common definition of sustainable development is development that meets the needs of today without reducing the ability of future generations to meet their own needs. The definition of concepts such as equality and social justice as well as environmental awareness generation in the covers [5]. Richard Rogers and other experts with a focus on sustainability in their work for a planet as small towns, the public sphere as a factor of social incentives and mobility in urban areas is introduced. Because it believes that a sustainable city must have a characteristic such as justice, beauty, creativity, ecology, compactness and multicenter, diversity and ultimately the easy communication of information, as well as face-to-face and electronic exchange [6]. Given the importance of green spaces in urban sustainable development and quality of life of the inhabitants of the cities studied the issue from different perspectives by researchers placed. Charmauf in book areas of public life and private life in 1376, writes that the destruction of human life is private car. Believed to be as far as possible with availability of free public transport for people to be encouraged not to use private vehicles [7]. Saeednias book of urban green space, 1382 argues the different aspects of urban green spaces [8]. Hatami nezhad in 1389 to study the patterns of spatial distribution of urban green spaces in Mashhad and the need for citizens to have green spaces [9]. In August 1990, the United Nations Centre for Human Settlements in formulating concepts with regard to human settlements agendas and developing approaches, "the sustainable city" officially started [10]. According to Alkin in 1991, "sustainable development is more than just the environment. And the need for equality in housing. Equality in a generation to meet the needs of the poor segments of society and equality between generations, to meet the needs of future generations". Alkin and colleagues reported in 1991 [11]. Sustainable urban development that meets the needs of its users and to make the city not only in terms of energy efficiency but also in terms of performance as well as a good place to live. Bernie in 1992 stated that "success in achieving the goals of sustainable urban development requires the provision of urban development and providing equal conditions for the present generation and future. The reserves of natural resources should not be used beyond its capacity to regenerate. The main street in the city of Rasht, the head of the Ramblas in Barcelona, Spain and the Netherlands in Copenhagen Astrvgt urban Curitiba in Brazil, are examples of such spaces [12]. Chysvra (2004), the article also pointed out the importance of sustainable urban parks, urban green spaces and the lack of international studies in this field, has worked for the welfare of the citizens of the importance of nature and sustainability show. The results, he acknowledges that the experience of nature into the urban environment is a source of positive emotions and good services to non-material human needs and to meet the spiritual significance [13]. Mylvard 2011 article the advantages of an urban forest park argue that urban forest parks, social services, environmental and economical numerous measurable value to provide cities. The ability to walk, mixing land uses and activities, appropriate density of people and businesses, combined air and space activities have created a public footpath that underlie these activities [14]. 


\section{Theory}

\subsection{Sustainable Development}

The term sustainable development was first officially reported "our common future" by Brandt Land in 1987. This broad sense of the term to include "accurate and efficient management and utilization of basic resources, natural resources, financial resources and manpower to achieve desired consumption patterns associated with the use of technical facilities and organizational structures for the needs of future generations present and future continuous and satisfactory [15]. Sustainability means meeting the current needs without destroying the ability of future generations to meet their own needs. The main result of developments in the contemporary of dominance in technology and the economyThe main result of developments in the contemporary of dominance in technology and the economy،this is the human complete isolated from nature, definitely has located he in a way destruction of the environment and the loss of environmental conditions on Earth [16].

\section{Characteristics of a sustainable city}

- reduce reliance on the car (especially private cars) in the displacement

- Increased physical compactness and urban development

- protection and restoration of natural systems in the city and surrounding area

- reduction of resource consumption and pollution generated in the city and its region

- improvement of urban environment

- Therefore, stability and strengthening the urban economy

- administrative and governance reform [17].

\subsection{Is the Green Area of the Social Dimension, a Sustainable Environment}

The social dimension of public spaces based on the triangle of man, space and collective life that these aspects requires attention to the following address:

- Understanding human needs in terms of space and knowledge of different groups using the space

- Understanding the physical dimensions of public space and its features in relation to the social dimension of space

- effectively recognizing the collective life of our existing portfolio and provide opportunities for physical and social activities for development [18].

Green spaces, including spaces that convey a sense of social space and to allow people to learn from others. They also created an opportunity to express their personal and social value, will inspire your spiritual growth and overall green space to allow its users to feel the freedom and independence Green, natural environment into the urban environment is a harsh environment made of artificial tissues to convert a relaxing environment, and colors of eye-catching, ear-catching soundtrack to the spirit of man is ready to tackle the challenges of urban life [19]. Green space between the community and the natural environment and thus establishes a strong relationship between the city more habitable and more tolerance [20]. On the other hand, is a measure of the quality assessment of each city, there are public green spaces, spaces that citizens are able to interact and negotiate with each other for safety and comfort, The importance of this issue to the extent that attention to urban green spaces in towns and apply policies from problems such as despair avail and the relationship with the environment the green spaces of the main functions of the city is institutions [21]. Design of green space, physical space and today this space as long as a suitable space, which can be of social, cultural and psychological stress can have positive [21]. Therefore, today's urban landscape can be in different countries as one of the main themes in the evolution of social and psychological dynamics of the citizens know, Awkward social sustainability in cities today is one of the aspects of a city stable and garden in the presence of people in space, so it can be responsive environment for this purpose should include a set of qualities.

\subsection{Respondents Environment}

Mobile agents of the city, especially the people and their activities, as the image of any city in the minds of the people affected by the same factors not only citizens but also part of its supervisory landscape. Environments that are responsive environment to maximize the range of options offered by the people, a democratic environment to provide users [24]. Organisms to survive an environment in which they prefer. In contrast environments that inhibit their growth or to harm them do not know good, human favorable environment in which all those human capabilities can be more effective and better meet their needs. People are searching for new information but the information cannot be used to understand and also hate them. "Reciprocity and the effects of "urban design quality" to "quality of life" is stressed city dwellers by Kevin Lynch. He says: "If urban planning is to be useful to be able to through the last decade." The quality of the physical environment, "the last decade" quality of life "to help people" [19]. Quality urban design consists of three components called "experimental quality - aesthetic", "performance" and "environmental quality". According to psychologists, all people based on their personal experience of the environment, there are personal impressions of the places [20]. Continuity and quality of the human know environment through spaces that comprise the areas that are used most [20].

\subsection{Qualitative Criteria for Measuring the Space for Theorists}

About the theory, many theorists have tried to arrange Criterion of an urban space that you can use them to Jacobs, Lynch, Aplyard, Tybaldz, Carmona, Pakzad, etc.

In the table below we have collected some of these criteria. 
Table 1. Comparison of different views about the quality of the urban environment.

\begin{tabular}{|c|c|c|c|c|c|c|}
\hline theorists & $\begin{array}{l}\text { Carmona } \\
2003\end{array}$ & DETR 2000 & $\begin{array}{l}\text { Pantr and } \\
\text { Carmona } 1997\end{array}$ & $\begin{array}{l}\text { New Urban Development } \\
\text { Congress } 1993\end{array}$ & Francis Tybaldz 1992 & $\begin{array}{l}\text { Allen, Jacobs, Donald, } \\
\text { Aplyard } 1987\end{array}$ \\
\hline \multirow{6}{*}{ criteria } & Available & Identity & $\begin{array}{l}\text { Quality stability } \\
\text { Environmental }\end{array}$ & $\begin{array}{l}\text { Register and population } \\
\text { diversity Neighborhood }\end{array}$ & $\begin{array}{l}\text { The design places priority } \\
\text { on other construction }\end{array}$ & Capable of living \\
\hline & $\begin{array}{l}\text { Hard and soft } \\
\text { space }\end{array}$ & $\begin{array}{l}\text { Continuity } \\
\text { and enclosure }\end{array}$ & $\begin{array}{l}\text { Landscape of } \\
\text { city }\end{array}$ & $\begin{array}{l}\text { Design environment } \\
\text { To walk and move }\end{array}$ & $\begin{array}{l}\text { Learning from the past and } \\
\text { respect the field }\end{array}$ & Control and identity \\
\hline & Public space & $\begin{array}{l}\text { Quality } \\
\text { public realm }\end{array}$ & Quality views & $\begin{array}{l}\text { Availability of cities with } \\
\text { public spaces for } \\
\text { pedestrians }\end{array}$ & $\begin{array}{l}\text { Integration of applications } \\
\text { and Activities }\end{array}$ & $\begin{array}{l}\text { Access to opportunities, } \\
\text { ideas and pleasures }\end{array}$ \\
\hline & $\begin{array}{l}\text { Safety and } \\
\text { security }\end{array}$ & $\begin{array}{l}\text { Ease of } \\
\text { movement }\end{array}$ & Quality of form & According to local history & Human-scale design & Means \\
\hline & $\begin{array}{l}\text { Mixing and } \\
\text { compaction }\end{array}$ & Readability & $\begin{array}{l}\text { Quality form } \\
\text { Building }\end{array}$ & Due to weather & $\begin{array}{l}\text { Promoting freedom of } \\
\text { pedestrians } \\
\text { Implementation }\end{array}$ & Public life Social \\
\hline & $\begin{array}{l}\text { Urban } \\
\text { Landscape }\end{array}$ & Flexibility & $\begin{array}{l}\text { Quality public } \\
\text { realm }\end{array}$ & According to ecology & $\begin{array}{l}\text { Creating environments } \\
\text { legible and clear }\end{array}$ & Self in \\
\hline
\end{tabular}

Concepts of urban design qualities of urban environment by scholars, raised and presented in Table 1, May vary in some cases and in many cases have common concepts that have been expressed with different words. Therefore, the outcome of these concepts in a summary should be provided. According to the authors, these concepts can be brought in 6 common sense. These concepts are responsive to the environment, including "vitality, diversity, environmental sustainability, flexibility, richness of sensory, safety and security". Patterns of social interaction and capabilities of the built environment are important because of the social interaction and belonging to the social and built environment, there is a close link. So a green space to meet the needs of the people (functional, environmental, aesthetic) is a responsive environment and this has resulted in people and freedom independence and the establishment of social interactions in space and social stability there.

\section{Case Study: Garden of Imam Reza (AS), Koohsangi. St, Mashhad}

Mashhad city, about 475 kilometers across. This city is Iran's second largest city and the most populated after Tehran in terms of religious, economic, industrial. General Population and Housing Census 1385, the population of the city this year, more than 2,410,800 persons. The geography of tourism, religious places as a powerful pole of attraction in the city, and in iran "Mashhad" is known travelers the biggest shrine.

The city has 13 metropolitan areas. The region studied in this paper (Garden Alndsht) situated 8 in Mashhad. PSI Mashhad (parks, squares and gardens) about 5 square meters, so that Mashhad has 200 Parks, 2 Forest Parks, 11 City parks, 37 regional parks, 42 neighborhood parks, and 109 neighborhood parks with a total area of 550 hectares. In addition to parks, gardens such as Malek abad garden, the garden of Imam Reza (AS) (garden Alndsht) and Astan Quds garden with historical records are located in the city. Given that this amount is much lower than the level of international standards and Garden Alndasht is one of the great gardens of the city, Razavi holy shrine is under the management of gardens, garden maintenance and preservation while maintaining the presence and activities of people was special. The garden with an area of 10 hectares. Koohsangi Street, geographically within $36^{\circ} 17^{\prime} 13$ "geographic length 59 $34^{\prime} 48^{\prime \prime}$ is located.

\section{Data Analysis}

The 112 questionnaires were randomly have been questioned in the koohsangi's pedestrians area, of which 64 women and 48 men. According to statistics, most of them had been responding to questions aged 26 to 50 years with education diplomas.

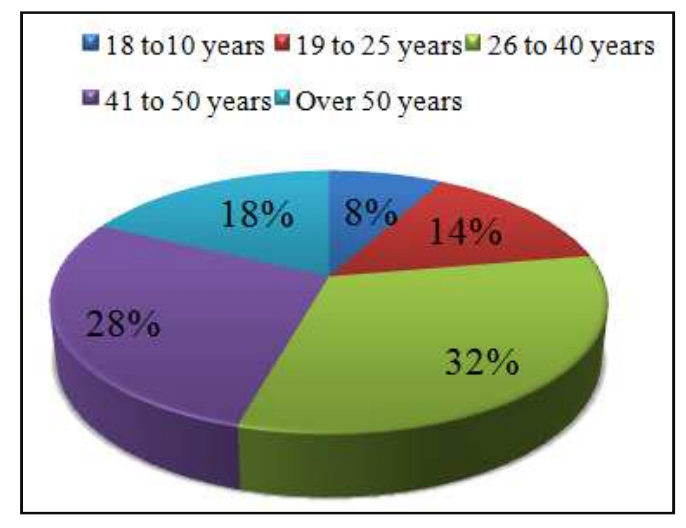

Figure 1. Age Population.

Also, 44 percent of pedestrians more than 5 to 10 times a week are walking in the sidewalk, and we can certainly see and experience better results in this study.

Table 2. Passes in front of the garden on a weekly basis.

\begin{tabular}{lll}
\hline Percent & Abundance & Variable \\
\hline 25 & 28 & 0 to 2 Times \\
17.9 & 20 & 2 to5 Times \\
13.4 & 15 & 5 to 10 Times \\
43.8 & 49 & More than 10 times \\
100 & 112 & Total \\
\hline
\end{tabular}


The following table shows sustainability-environment that most people prefer to watch passages around the garden in the early hours of the morning or in the evening. It shows the elegance and comfort of clean air, climate, and the essential requirement of today's life. Something that becomes all times, especially nowadays feel more desirable range due to the air, it has provided comfort to citizens. Also, about 60 percent of people prefer to walk the path of only $22.3 \%$ want to use their personal vehicle to cross the road and attention to the beauty of the garden can be a cause of these statistics.

Table 3. The transit time from the front of garden.

\begin{tabular}{lll}
\hline Percent & Abundance & Variable \\
\hline 50.9 & 57 & Morning \\
1.8 & 2 & Noon \\
33 & 37 & Evening \\
14.3 & 16 & Night \\
100 & 112 & Total \\
\hline
\end{tabular}

The number of people are wish to enter garden, as can be seen in Table 4 show that half of them have a passion for entry even if it closed. There is a correlation between age and willingness to enter the garden. At the age of 10 to 18 years of interest in this area is equal, (except the great desire that the abundance is less). 19 to 25 year age group often have a high tendency to enter the garden. Other age groups, a great desire to enter their gardens.

Table 4. The tendency to enter the garden 4. Using the Template.

\begin{tabular}{lll}
\hline Percent & Abundance & Variable \\
\hline 52.7 & 59 & A lot \\
17.9 & 20 & High \\
14.3 & 16 & Average \\
5.3 & 6 & Low \\
9.8 & 11 & Very little \\
100 & 112 & Total \\
\hline
\end{tabular}

It is interesting that in 53 percent of pedestrians, User Account perfect harmony with the surrounding garden, and this situation can be found in the chart below, where qualities such as clean air, memorable and relative safety can be outlined. Among the qualities of air purity vitality and memorable first and then the second, third, and ultimately the safety of pedestrians in the park is an attraction. In terms of diversity - it is interesting that in 53 percent of pedestrians, User Account is perfect harmony with the surrounding garden. A wide variety of uses for garden residents are appropriate and surrounding land is not compatible. Then the importance of qualities such as clean air, memorable and relative safety were assessed in relation to the garden space. Among these qualities, purity of air in the first place, followed by lively and memorable in the second and third and finally the safety of pedestrians in the garden is attractive.
Table 5. Uses attractive features.

\begin{tabular}{lll}
\hline Percent & Abundance & Variable \\
\hline 29.5 & 33 & Vitality \\
42 & 47 & Clean air \\
22.3 & 25 & Memorable \\
6.3 & 7 & Relative security \\
100 & 112 & Total \\
\hline
\end{tabular}

- Security of the fact that 46 percent of those polled have deemed it necessary to further Lighting.

- Such relative can be said that this area of security, and this factor has little traffic during the day, night falls.

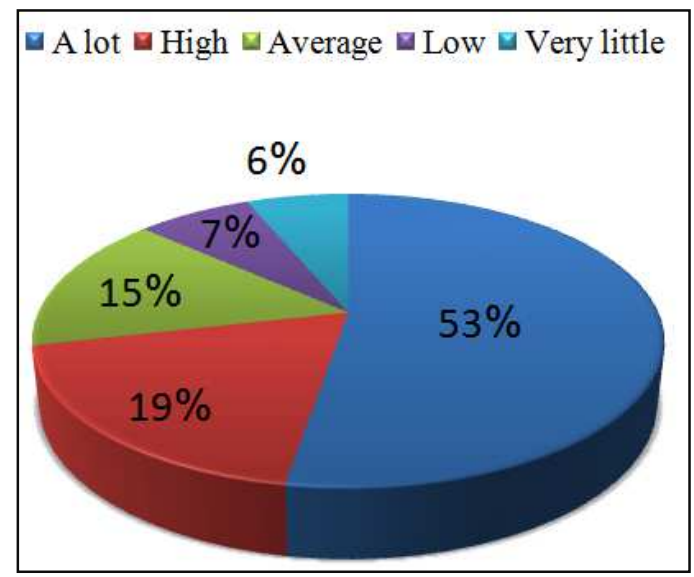

Figure 2. Garden of harmony with the surrounding buildings.

Track mounted and dismounted separation has caused 59\% of the way as walking or cycling route to choose. Also, many people tried to cross the road instead of passenger vehicles, bicycles or even walking on the bike take advantage and are preferred.

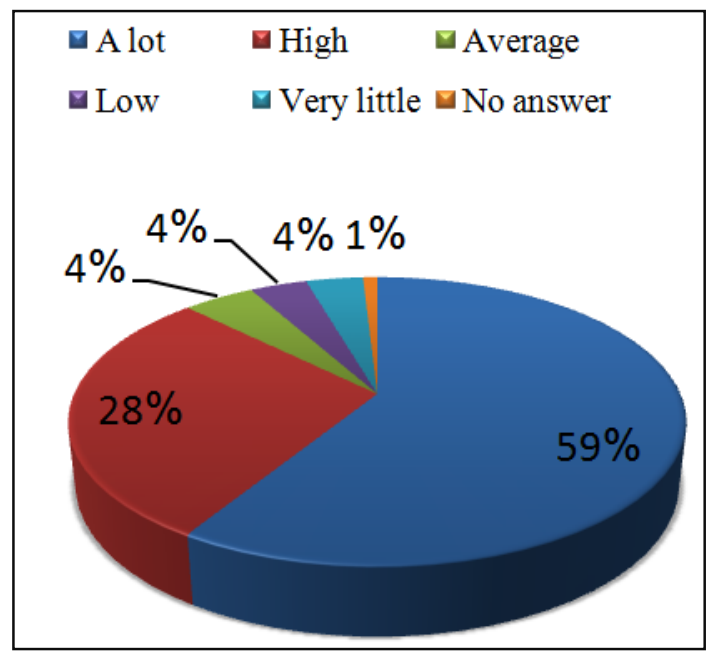

Figure 3. The tendency to walk on the road.

Given above and the following diagram can be concluded that the destruction of the garden in any of the residents is not acceptable. Because most people use to meet environmental and social needs. It is also appropriate to improve the quality of urban social behaviors emerging as the only thing that 
people talk in terms of economic needs of the people. User not absorbent so that the walled garden has diversified its activity is lost and vitality because of the way most people do not stop - pause their activity. That's why 16 percent of people in the preservation of the garden in the form and manner satisfactory to date And nearly 84 percent of people with regard to the needs prefer to garden with little change, more attractive for them to bring.

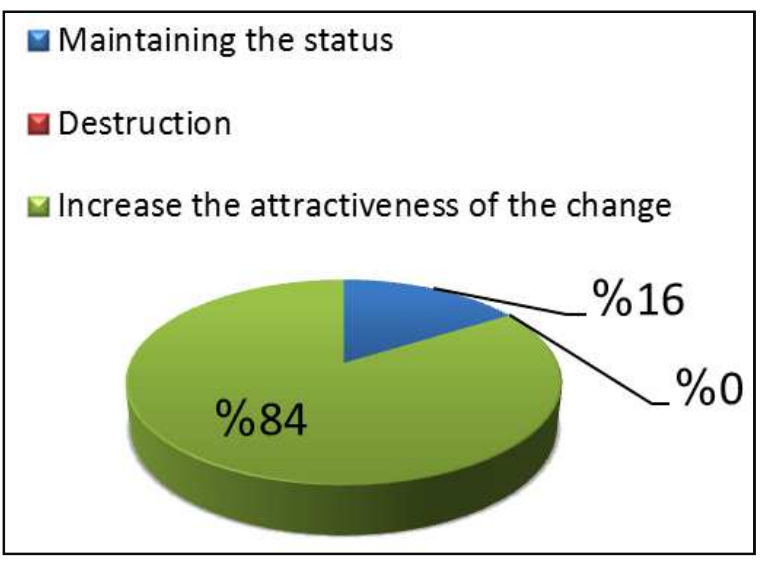

Figure 4. Desired future for the garden.

However, it changed how and by how much body pinch garden, you must create an attraction. The residents were asked the following proposed several options that you can see it in the chart and table below. The walking and bicycle path through the garden space, parks and recreation areas for children and adults, and cultural space look almost the same percentage view.

Table 6. How to use the garden.

\begin{tabular}{lll}
\hline Percent & Abundance & Variable \\
\hline 31.3 & 35 & Pedestrian and bicycle route \\
27.7 & 31 & Parks and recreation areas \\
29.5 & 33 & Cultural space \\
6.3 & 7 & Commercial space \\
5.4 & 6 & Current pristine condition \\
100 & 112 & Total \\
\hline
\end{tabular}

And the chi-square test between the age and condition of the garden there is a correlation in the future. All age groups tend to maintain the garden at the same time increase its attractiveness.

\section{Discussion and Conclusion}

In this article, the response rate in most urban areas of greenery (garden) with historical value "identity and memorable" review. The material in this article was gathered stable and responsive space should use criteria such as diversity, vitality, sustainability, environment flexibility, sensory richness of safety and security to be considered. Differently it can be said that if one space answer to three needs: environmental need, functional and aesthetic Simultaneous, this space without a doubt will be responsive for users. In urban areas, but as a whole it will be same, prioritize is move possible. As noted above, urban green space to the open spaces and greenery is said that in urban environments with clear objectives, plans and certain actions are based upon responsible them. The urban landscape of broad or narrow spaces in the city's functional range selected for adding variety and beauty, the quality of life, human welfare and provide special services to the citizens and been by a variety of native vegetation, under the supervision and management of the urban human. The subject of this article Garden of Imam Reza (Alandsht Garden) to encompass quality of aesthetic and environmental plays a major role in the pedestrian's psychological comfort on the Koohsangi Avenue and by taking into account the statistical results obtained through questionnaires and statistical studies of society, it can be concluded that the garden space, in addition to aesthetic aspects, plays a major role in functional and psychological needs of the people. according to the surveys, people will concent to little change in the garden, to the extent that not harm to identity garden and don't decrease garden's memorable. This change by adding a proportional user with the green space user or according to needs people can be. The New Positioning only in order to increase the amount of social interactions will occur and with an increase in the use of public space will be reduse to the functional quality. in that case the people continue to maintain it over time, and will participate to the development of appropriate and varied use of the land it. With making a sense of participation of the people as a result of the quality of garden's response to the public, in addition to reducing the cost of maintaining the Alandasht Garden, the user will remain in the minds. Also according to analyzed the figures in the article to the conclusion that urban green spaces is one of the most valuable land in the city that everyone should be diligent in maintaining it.

\section{References}

[1] D. Ardalan and Z. Davoudpour "A comparative study of factors affecting the development of large and middle cities" Journal of the town's identity, Issue 3. payyz and winter 2008, p 64.

[2] S. Pamir, "The creation of a vibrant urban center", translation Mostafa Behzadfar and Amir Shekiba manesh, University of Science and Technology, Tehran, 2009, p 34.

[3] N. Schulz, "spirit of the place: in the phenomenology of architecture", 1980, p 166.

[4] V. Moradi masihi, "The urban and environmental performance, in sustainable urban form", 2004. P 6.

[5] R. Rogers, "Cities for a Small Planet", Published: Jul 24, 1998 Publisher: Basic Books, 196 Pages.

[6] Chermayeff, Ivan Sergei, private and public spheres of life, translator M. ornate, Tehran University, Tehran, 1997.

[7] A. Saidnia, book municipalities, Volume IV: the urban centers and residential areas, publications, organizations, municipalities, Tehran, 2003. 
[8] Sustainable Cities Program (SCP), 1990-2000, Publisher: UN-Habitat. P 81.

[9] R. Maknoon, "Sustainable Development", Environment Experts Association's magazine, the first issue, 1995.

[10] S. H. Bahrain, 1376. Urban Planning and sustainable development. Journal of approach. 17. s number 28, 1997.

[11] K. Ziari, M. H. Janbabanezhad. "Views and opinions healthy city", Monthly municipalities Title No. 95, 2009.

[12] S. A. Daneshpour, M. Charkhchian, "Public spaces and factors affecting collective life", Volume 4, Issue 7, 2007, page 19-28.

[13] K. B. soltani, "Basics of Architectural urban green space", Publications Tehran, View, 2005.

[14] Jean Bastyh Bernardez, "City", translator Ashrafi, 1998, Publications of Tehran, University of Art.
[15] A. Madanipour, "Urban space design concept on the social and spatial process", 2000, translator F. Mortezaii.

[16] K. Lynch, "Urban theory since A Theory of Good City Form", 1981.

[17] Bentley, 1. et al. "Responsive Environments", 1985, A manual for designers", Architectural, London.

[18] Stephen Kaplan, Rachel Kaplan. "Humanscape: Envaironment for people", 1978.

[19] IR Beer and Catherine Higgins (1941), “environmental planning for land development" translator Hussein Bahrain, K. Karim, Tehran University.

[20] Golkar, Cyrus, "constructive quality urban design". Journal of Sfh. mahshahr32. 2000, 38-65. 